\title{
Components of breeding performance in two competing species: habitat heterogeneity, individual quality and density-dependence
}

\author{
Martina Carrete, José A. Sánchez-Zapata, José L. Tella, José M. Gil-Sánchez and Marcos Moleón
}

Carrete, M., Sánchez-Zapata, J. A., Tella, J. L., Gil-Sánchez, J. M. and Moleón, M. 2006. Components of breeding performance in two competing species: habitat heterogeneity, individual quality and density-dependence. - Oikos 112: 680-690.

\begin{abstract}
Density-dependent breeding performance due to habitat heterogeneity has been shown to regulate populations of territorial species, since the progressive occupation of low quality territories as breeding density increases may cause a decline in the mean per capita fecundity of a population while variation in fecundity increases. Although the preemptive use of sites may relegate low quality individuals to sites of progressively lower suitability, few studies on density dependence have tried to separate the effects of territory quality from individual quality, and none have simultaneously considered the effects of heterospecific competitors. Using two long-term monitored populations, we assessed the relative contribution of habitat heterogeneity and bird quality (in terms of age) on the productivity of sympatric golden Aquila chrysaetos and Bonelli's eagles Hieraaetus fasciatus under different scenarios of intra- and inter-specific competition. Productivity (number of offspring fledged) varied among territories and average annual productivity was negatively related to its variability in both species and populations, thus giving some support to the habitat heterogeneity hypothesis. However, the effect of habitat heterogeneity on productivity became non-significant when parental age and local density estimators were included in multivariate analyses. Therefore, temporal changes in bird quality (age) combined with intra- and interspecific competition explained variability in territory productivity rather than habitat heterogeneity among territories per se. The recruitment of subadult breeders, a surrogate of mortality in eagles, strongly varied among territories. Habitat heterogeneity in productivity may thus arise not because sites differ in suitability for reproduction but because of differences in factors affecting survival. Territories associated with high mortality risks have a higher probability of being occupied by young birds, whose lower quality, interacting with the density competitors, leads to a reduction of productivity. Sitedependent variability in adult survival and interspecific competition may be extensive, but so far largely overlooked, factors to be seriously considered for the site-dependent population regulation framework.
\end{abstract}

M. Carrete and J. L. Tella, Dept of Applied Biology, Estación Biológica de Doñana (CSIC), Avda. M. Luisa s/n, ES-41013, Sevilla, Spain (martina@ebd.csci.es). - J. A. Sánchez-Zapata, Dept of Applied Biology, Univ. Miguel Herná ndez, Ctra. de Beniel km 3.2, ES-33012, Orihuela, Alicante, Spain. - J. M. Gil-Sánchez and M. Moleón, Dept of Animal Biology and Ecology, Univ. of Granada, ES-18071, Granada, Spain.

Because population regulation is the emergent pattern of population dynamics that promotes the most intense debates among ecologists (Rodenhouse et al. 1997, Hawkins and Berryman 2000, Berryman 2002, 2004, Hunt and Law 2004), an understanding of the factors and mechanisms that regulate population numbers is a key in population ecology (Nilsson 1987, Newton 1998, Turchin 1999). Habitat heterogeneity and despotic settlement have been postulated as the main mechanisms of population regulation for territorial birds (Dhondt 
et al. 1992, Ferrer and Doná zar 1996, Krü ger and Lindströ m 2001, Sergio and Newton 2003). Combined under the traditional density-dependent population regulation theory (Fretwell and Lucas 1970, Hawkins and Berryman 2000) or the site-dependence hypothesis (Rodenhouse et al. 1997, 2000), these scenarios predict that the progressive occupation of low quality territories as breeding density increases causes a decline in the mean per capita fecundity of a population while variation in fecundity increases.

Several studies have supported the habitat heterogeneity hypothesis by correlating variation in the mean annual reproductive output of a population with its coefficient of variation (Ferrer and Doná zar 1996, Blanco et al. 1998, Krü ger and Lindströ m 2001, Penteriani et al. 2003, Sergio and Newton 2003), or by relating variation in mean territory productivity to territory occupancy (Sergio and Newton 2003). However, although the negative feedback generating densitydependence through this mechanism results because the pre-emptive use of sites may relegate low quality individuals to sites of progressive lower suitability (Fretwell and Lucas 1970, Rodenhouse et al. 1997, Newton 1998, Pärt 2001, Kokko et al. 2004), most studies concentrate just on one of these topics, i.e. habitat or individual quality, or the available data do not allow the proper separation of their relative importance in the studied populations.

The concept of individual quality was mainly proposed to emphasize the fact that not all individuals in a population are equal (Coulson 1968). Among birds, for example, reproductive success often increases with age during the first years of life. Thus, subadults, which are usually less productive than adults, could be considered as low quality breeders during that period of their life (reviewed by Forslund and Pärt 1995). Several studies, however, suggest that young individuals often breed in worse habitats than older breeders (Cody 1985, Bernstein et al. 1991, Newton 1998, Pärt 2001), and thus the improvement in reproductive performance may not only be a consequence of improvements in breeding experience, mate experience and foraging ability, but also because of the access to high-quality habitats with age (Pärt 2001).

On the other hand, interspecific competition may have demographic consequences in territorial species which compete for resources linked to space (Schoener 1983, Hakkarainen and Korpimäki 1996, Eccard and Ylönen 2003, Hakkarainen et al. 2004, Carrete et al. 2005). In the simplest case, two species that exhibit territoriality can coexist and fill the habitat by compressing their exclusive areas. The space is then occupied until reaching the carrying capacity, and then no more birds can settle unless they displace others. Territories and home ranges of sympatric species can also overlap and then exploitative and/or interference competition among them may arise (Hakkarainen et al. 2004). These mechanisms may regulate the combined density of both species acting in a density-dependent manner and affecting the reproductive output of one or both species, depending on their competitive abilities or habitat requirements (Wiens 1989, Hakkarainen et al. 2004, Holt et al. 2004). Finally, if we extend the traditional single-species despotic distribution to a two-species system, the breeding performance of a species could be reduced because the presence of a superior competitor displaces individuals to low quality sites (Rosenzweig 1979).

The aim of this paper was to assess the relative contribution of habitat heterogeneity, intra- and interspecific densities, and parental age on the breeding performance of two species competing for resources, using the golden eagle (Aquila chrysäetos ) and Bonelli's eagle (Hieraaetus fasciatus ) as a model. The distribution ranges of these territorial raptors overlap in the Mediterranean area, where they share prey (mainly rabbits Oryctolagus cunniculus) and cliffs for nesting (del Hoyo et al. 1994), occupying similar habitats and interchanging territories (Carrete et al. 2005). Previous works have shown that breeding performance of subadults is poorer than that of adult breeders in both species (Steenhof et al. 1983, Sánchez-Zapata et al. 2000, Pedrini and Sergio 2001, Carrete et al. 2002a, Penteriani et al. 2003), while there is little evidence for density-dependent effects on reproduction for the golden eagle in central Europe (Haller 1982). Although interspecific competition for food and/or nesting sites with golden eagles, which are larger and heavier (ca $4 \mathrm{~kg}$ ), has been frequently proposed as a problem for the recovery of the smaller Bonelli's eagle (ca $2 \mathrm{~kg}$; del Hoyo et al. 1994, Gil-Sá nchez et al. 2004, Ontiveros et al. 2004), nothing is known about the combined effects of intra- and interspecific densities, and their role with respect to breeder's age and habitat quality, where both eagles are sympatric.

We took advantage of two long-term monitored study areas, where densities and population traits of the two eagles are different, to contrast the effects of habitat heterogeneity and individual quality (in terms of age) on breeding performance under different scenarios of intraand inter-specific competition. We first tested general predictions derived from the site-dependent population regulation (Sergio and Newton 2003), namely: 1) under a scenario of habitat heterogeneity, populations are structured in territories of different quality, 2) mean population breeding performance should decrease as breeding density increases, 3) thus increasing the variance in breeding performance, and 4) breeding performance should be better in higher occupancy territories than in lower ones. Second, we tried to separate the effects of habitat quality, bird quality and competition through multivariate analyses, testing the following predictions: 5) if age affects reproduction per se, breeding perfor- 
mance of subadults should be poorer than that of adults while controlling for territory quality, 6) the proximity of other territories should negatively affect breeding parameters, 7) inter-specific densities should play a major role for the smaller, supposedly less competitive species (Bonelli's eagle), and 8) if subadults are less competitive than adults when defending nesting and/or foraging areas from other eagles, an interaction between age of breeders and densities should arise, i.e. the effects of intra- and/or inter-specific densities on reproduction should be stronger for territories occupied by subadults. These predictions were tested within each eagle population separately, and the results obtained were then compared to assess whether the strength of relationships varied among areas and species showing different population densities.

\section{Methods}

\section{Study areas and eagle populations}

Field work was carried out in two large areas located in south-eastern (Murcia province, $11317 \mathrm{~km}^{2}$ ) and southern Spain (Granada province, $12647 \mathrm{~km}^{2}$ ), where eagle populations present differences in their breeding densities as well as in their population balances. Although Murcia had one of the highest densities of Bonelli's eagles in the 1980's, its population declined considerably (from 35 pairs to 17 pairs) between 1983-1990, when the population stabilized. Since 1998, the population has increased to 24 breeding pairs in 2001. Contrarily, the golden eagle population seems to have been stable in recent years (around 44 breeding pairs, Carrete et al. 2002a, 2002b). In Granada, the number of Bonelli's eagle pairs oscillated less $(43-51)$ than in Murcia, and the golden eagle population was quite stable (ca 60 pairs). At the end of this study (2001-2003), densities of both species were higher in Granada (Bonelli's eagle: 0.40 pairs $100 \mathrm{~km}^{-2}$; golden eagle: 0.49 pairs $100 \mathrm{~km}^{-2}$ ) than in Murcia (Bonelli's eagle: 0.21 pairs $100 \mathrm{~km}^{-2}$; golden eagle: 0.39 pairs $100 \mathrm{~km}^{-2}$ ), where they show a higher unbalance in the relative number of breeding pairs (i.e. the ratio between golden and Bonelli's eagles in Murcia is near two times the ratio observed in Granada). Thus, to avoid confusions with the areas, hereafter Granada will be called HDA (high density area) and Murcia LDA (low density area).

\section{Census and reproductive data}

We monitored the populations of Bonelli's eagles for 19 years (1983-2001) in the LDA and 10 years (19942003) in the HDA. The two sympatric populations of golden eagles were accurately surveyed only during the last five years (LDA: 1997-2001, HDA: 1999-2003), and therefore incomplete data from previous years are not considered here. All territories known to have been occupied by one of the species at least once during the study periods, as well as potential breeding areas, were annually prospected during the breeding season (January -July). Each cliff was carefully searched for eagles, their nests or other signs of occupancy. Occupied territories were located on the basis of territorial and/or courtship activity, and then repeated visits were conducted to record typical breeding parameters and finally the number of young that reached $80 \%$ of fledging age (i.e. around 50 days-old). Breeding output was measured as productivity, i.e. the number of fledglings raised per territorial pair (including pairs that did not lay clutches and total breeding failures) per year. Since the number of territorial pairs varied with years and not all nests were equally accessible for monitoring, sample sizes varied somewhat among years (HDA: Bonelli's eagle: 18-40 breeding events, Golden eagle: 24-32 breeding events; LDA: Bonelli's eagle: 12-22 breeding events, Golden eagle: 40-42 breeding events). Territorial birds were classified as either adults or subadults (i.e. less than five years old), according to plumage characteristics easily recognisable in the field (Forsman 1999). We defined an adult pair as one consisting only of adults, and a subadult or mixed pair as having at least one subadult bird.

\section{Breeding densities}

Changes in population breeding densities between years were measured as the change in the number of territorial pairs within each study area. Local breeding densities were annually measured at finer scales, using two different groups of variables. The first group included isolation variables $\left(S_{\text {total }}, S_{\text {intra }}\right.$ and $\left.S_{\text {inter }}\right)$, which describe the relative position of a territorial pair (measured as the geographical position of the nesting cliff in a given year, Carrete et al. 2001) within the spatial distribution of a set of pairs. They were calculated with a modified version of a classical formula used for metapopulation dynamics (Moilanen and Hanski 1998). Thus, the isolation of the breeding pair $\mathrm{i}$ was defined by $\mathrm{S}_{\mathrm{i}}=$ $\operatorname{Sexp}\left(-d_{i j}\right.$ ) (with $\mathrm{i}^{\prime} \mathrm{j}$ ), where $\mathrm{d}_{\mathrm{ij}}$ was the linear distance between pairs $\mathrm{i}$ and $\mathrm{j}$. Using this formula, we calculated $\mathrm{S}_{\text {total }}$ as the isolation of the pair $\mathrm{i}$ with respect to all the other pairs of the two species, $S_{\text {intra }}$ as the isolation of the pair $\mathrm{i}$ with respect to the conspecific pairs, and $S_{\text {inter }}$ as the isolation of the pair i with respect to the pairs of the sympatric species. Values of $S_{i}$ ranged from 0 to 1 , with lower values indicating higher isolation. The interaction variables ( $I_{\text {total }}, I_{\text {intra }}$ and $I_{\text {inter }}$ ) formed the second group of density variables used and may account for both prey exploitation and the antagonistic intra and interspecific interactions between the closest neighbouring pairs. We annually calculated the nearest neighbour distance for each pair (in meters), an index commonly used as a measure of territoriality in raptors 
(Newton et al. 1977, Katzner et al. 2003), where $I_{\text {total }}$ was the distance between pair $\mathrm{i}$ and the closest pair of any of the two species, $I_{\text {intra }}$ was the distance between pair $\mathrm{i}$ and the closest conspecific pair, and $I_{\text {inter }}$ was the distance between pair $\mathrm{i}$ and the closest pair of the sympatric species.

\section{Statistical analyses}

Differences in productivity, age structure, and local breeding densities between eagle populations were tested using nonparametric statistics. Also at the population level, relationships between annual breeding densities, average productivities, and their $\mathrm{CV}$, as well as relationships between average productivity of territories and their occupancy rate, were assessed by Spearman rank correlations (Sergio and Newton 2003). At a finer scale, we performed generalized linear mixed models (GLMM, McCullagh and Searle 2000) to untangle the factors explaining variance in productivity (Hakkarainen et al. 2004), using the Poisson distribution as link and error functions for discrete positive data (i.e. the number of young fledged per territory and year as dependent variable). We first explored the existence of habitat heterogeneity by testing the effect of territory (as a fixed effect) on productivity, while controlling for year as a random effect. After that, we combined all potential effects (i.e. territory, isolation and interaction variables, and parental age) in the same GLMMs to assess their relative contribution. Although territory became nonsignificant in those models (Results), we also included territory and year into GLMMs as random terms to control for the possible effects of spatial and temporal heterogeneity on reproduction and for non-independence of data (McCullagh and Searle 2000). A forward stepwise procedure resulted in multivariate models where only significant effects were retained. In the construction of models for Bonelli's eagles we first tested the contribution of interspecific variables $\left(S_{\text {inter, }} S_{\text {total }}, I_{\text {inter, }}\right.$ $I_{\text {total }}$ ), thus using the 5-year data sets in which both eagle species were simultaneously monitored; in the case that none of these variables or interactions with others resulted significant, the rest of variables tested (age and intraspecific variables) covered the whole, larger study periods. For each significant model, we calculated the percentage of deviance explained (100> (100-deviance model $) /$ deviance $_{\text {null model }}$ ). Models were built separately for the LDA and the HDA because a) study periods varied slightly between populations, b) breeding and density parameters differed significantly between populations, and c) accurate parameters for secondorder interaction terms (e.g. effects of population $>$ age $>$ density variables) are difficult to estimate. Analyses were made with SAS package (Littell et al. 1996).

\section{Results}

Differences between populations in productivity and density parameters

Population parameters and tests are provided in Table 1. Productivity of both eagle species was higher and more stable (i.e. with lower CV) in HDA than in LDA. The spatial arrangement of breeding pairs also differed between the two study areas, both when considering the distribution of conspecifics and heterospecifics, and the total number of eagle territories. The proportion of subadult pairs, however, did not differ between areas.

\section{Evidence for habitat heterogeneity and site-} dependent population regulation

Productivity significantly varied among territories in both populations of Bonelli's eagle and in the golden eagle population of the LDA, but not in the HDA (Table 2). Prediction 1 is thus partially supported, suggesting that habitat heterogeneity may structure three out of the four populations in territories of low and high quality. Nonetheless, variability in productivity explained by territory (while controlling for year effects, which were not significant) was rather low, as shown by the deviance explained by the models $(0-23 \%$, Table 2$)$.

Average annual productivity of Bonelli's eagles was negatively correlated to the annual number of breeding pairs $\left(\mathrm{r}_{\mathrm{s}}=-0.73, \mathrm{p}=0.017, \mathrm{n}=10\right)$ in the HDA (Fig. 1), as is expected if an increase in density reduces average productivity by occupying poorer territories. However, productivity of breeding pairs was positively correlated for the same species in the LDA $\left(r_{s}=0.61\right.$, p B0.001, $n=19$; Fig. 1). Therefore, prediction 2 where we expected that mean population breeding performance should decrease as breeding density increases was supported in the HDA but not in the LDA. This prediction could not be tested for the golden eagle given the stability of its populations during the study periods, and thus the absence of variability in the number of breeding pairs.

Prediction 3 is derived from the previous one: average productivity should be negatively correlated to its variance, due to the occupation of poorer territories when the number of breeding pairs increases. Consequently, it is surprising that prediction 3 was largely supported, despite the fact that prediction 2 was not: annual productivity was negatively related with its coefficient of variation for both the Bonelli's (LDA: $r_{s}=-0.95, p B 0.0001, n=19 ;$ HDA: $r_{s}=-0.96, p B$ $0.0001, \mathrm{n}=10$ ) and the golden eagle populations (LDA: $\mathrm{r}_{\mathrm{s}}=-0.90, \mathrm{p}=0.019, \mathrm{n}=5$; HDA: $\mathrm{r}_{\mathrm{s}}=-0.80, \mathrm{p}=$ $0.052, \mathrm{n}=5 ; 3)$.

Prediction 4 is derived from the previous ones in a context of habitat heterogeneity and site-dependent 


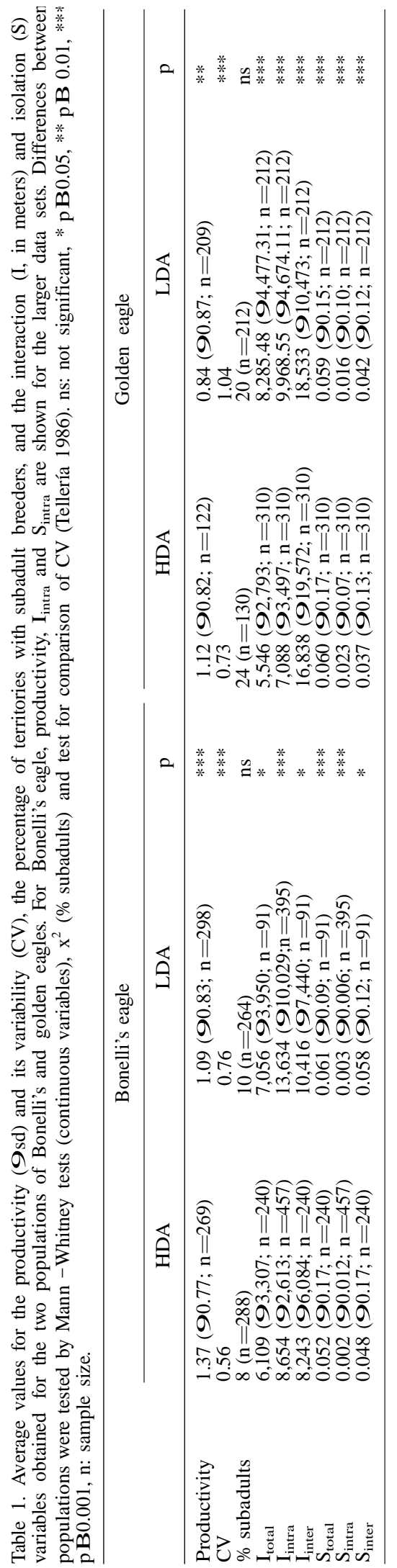

population regulation: the rate of occupancy of highquality territories should be higher than that of lowquality ones. This prediction was not supported, since average productivity of Bonelli's eagle territories was unrelated to the number of years they were occupied (LDA: $\mathrm{r}_{\mathrm{s}}=-0.34, \mathrm{p}=0.068, \mathrm{n}=29$; HDA: $\mathrm{r}_{\mathrm{s}}=0.05$, $\mathrm{p}=0.73, \mathrm{n}=44)$. As above, this prediction could be not tested for golden eagles due to the temporal stability of territory numbers.

Relative effects of habitat heterogeneity, parental age and local breeding densities on breeding performance

Generalized linear mixed models obtained to explain variability in the productivity of both populations of Bonelli's and golden eagles are shown in Table 3. Although habitat heterogeneity was partially supported before by significant differences in productivity between territories (Table 2), this effect became non significant when parental age or density estimators were included into the same GLMMs (range of $\mathrm{p}$-values for the fixed effect "territory": 0.11-0.30).

Parental age directly affected the productivity of both species in the LDA (it was the only explanatory variable), and through its interaction with local density variables (distance to the nearest neighbours) in the HDA (Table 3). None of the isolation variables, however, were retained as significant in the models. These results were obtained while controlling for the potential effects of territory and year fitted as random terms into the models, which were never significant (range of p-values for year: $0.27-0.49$, range of $p$-values for territory: $0.29-0.49$ ). Therefore, productivity was affected by parental age per se in both species and populations, thus wholly supporting prediction 5. The significant contribution of interaction variables also supported prediction 6, although their strengths varied depending on population breeding densities. While the productivity of subadult Bonelli?s eagles was low, irrespective of the intra- and interspecific local breeding densities surrounding a territory in the LDA, an interaction arose between parental age and the distance to heterospecific territories ( $\left.\mathrm{I}_{\text {inter }}\right)$ in the HDA. That is, subadults produced less fledglings than adults, and this effect was accentuated when they bred near to pairs of the supposedly dominant golden eagle (Fig. 3a). Consequently, prediction 7 was also supported. In the case of the golden eagle, the effect of parental age on productivity also varied depending on the population considered. In the low density area (LDA), subadults produced less fledglings independently of intra- and interspecific densities. However, an interaction between age and proximity to a conspecific territory ( $I_{\text {intra, Table } 3)}$ existed in the HDA: the poorer breeding output of 
Table 2. GLMMs to detect habitat heterogeneity (fixed effect: territory) through its effect on the productivity of two Bonelli's and golden eagle populations in low and high density areas (LDA and HDA, respectively). Year, included in models as a random effect, was not significant (p-range $=0.29-0.34$ ); DEV:\% deviance explained by the model. Significant models are shown in bold face.

\begin{tabular}{|c|c|c|c|c|c|c|c|c|}
\hline & \multicolumn{4}{|c|}{ Bonelli's eagle } & \multicolumn{4}{|c|}{ Golden eagle } \\
\hline & DF & $\mathrm{F}$ test & $\mathrm{p}$ & $\mathrm{DEV}$ & DF & F test & $\mathrm{p}$ & DEV \\
\hline HDA & 224 & 1.74 & 0.0054 & $23.12 \%$ & 75 & 1.26 & 0.1821 & \\
\hline LDA & 252 & 2.00 & 0.0088 & $2 \%$ & 154 & 1.70 & 0.0066 & $3.60 \%$ \\
\hline
\end{tabular}

subadults was accentuated when breeding close to another golden eagle territory (Fig. 3b). Altogether, prediction 8 was also supported.

\section{Discussion}

\section{Habitat heterogeneity and individual quality}

The strong negative relationship that we found between the mean annual productivity and its coefficient of variation has been interpreted as evidence of habitat heterogeneity in other bird populations, where successful reproduction occurs in good territories with little yearto-year variation and where the progressive addition of lower quality territories due to population growth decreases mean reproductive success and increases variability (Ferrer and Doná zar 1996, Krü ger and Lindströ m 2001, Penteriani et al. 2003, Sergio and Newton 2003). However, our study did not completely match with this density-dependent population regulation mechanism (i.e. effect of habitat heterogeneity on reproduction). Average productivity did not consistently decrease with breeding population size, and occupancy rate of territories did not correlate with their quality in terms of breeding performance. Although productivity tended to significantly differ between territories, thus giving support to the existence of habitat heterogeneity at the territorial scale, the spatial component (territory) disappeared when other individual and populational sources of variability in productivity (parental age, local breeding densities) were simultaneously tested in the same multivariate models. In fact parental age, whatever the hypotheses used to explain age-dependent breeding performance (Forslund and Pärt 1995), together with the relationships among neighbours, were the only factors related to the productivity of these eagle populations. Therefore, temporal changes in bird quality (age) and in the distribution of territories explained variability in territory productivity, rather than the physical aspects of territories. This conclusion agrees with our previous analyses which found few (if any) essential influences of habitat composition around nests on productivity of the same eagle populations (Carrete 2002, Gil-Sánchez et al. 2004, Hakkarainen et al. 2004).

It is not surprising that in nature a single pattern may arise from different processes. In this case, the negative relationship between mean productivity and its $\mathrm{CV}$, which is the only prediction supporting density-dependent population regulation through habitat heterogeneity, seems to simply arise from variability in parental age but not in territory quality. Despite the rather complex relationships between age and densities and their effects on productivity (Table 3), simple univariate tests show that the annual proportions of subadult pairs tend to negatively correlate to mean annual productivity ( $r_{\mathrm{s}}$ ranges: -0.60 to -0.90 , p-values: $0.26-0.006)$ and positively to its annual variability $\left(\mathrm{CV}: \mathrm{r}_{\mathrm{s}}\right.$ ranges: 0.36 to 0.90 , p-values: $0.55-0.003$ ) in both eagle species and populations.
Fig. 1. Relationships between average annual productivity (number of fledglings per territorial pair) and annual numbers of breeding pairs of Bonelli's eagle in the two study areas.
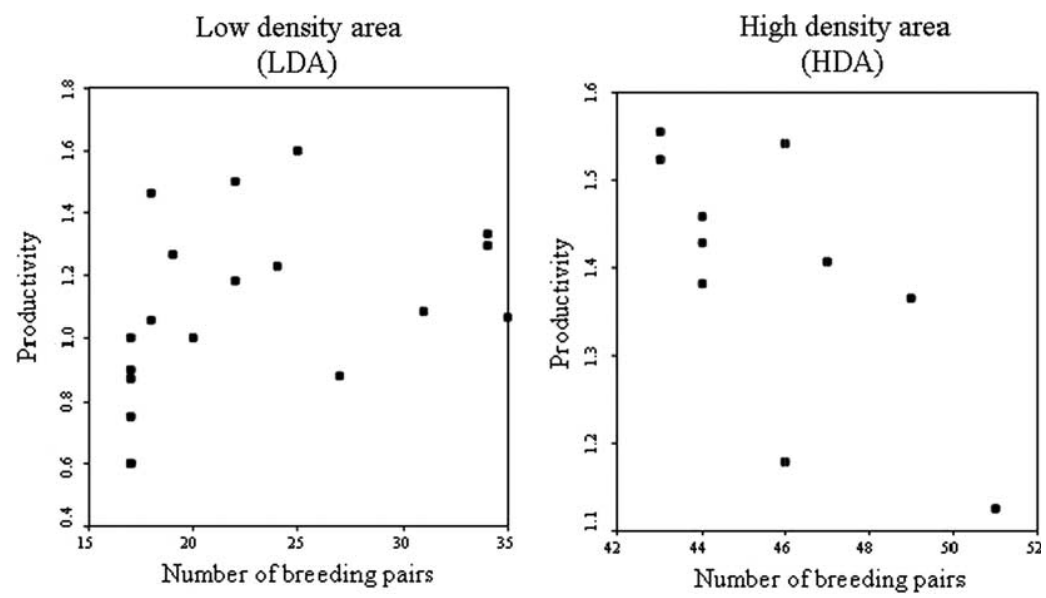
Low density area

(LDA)
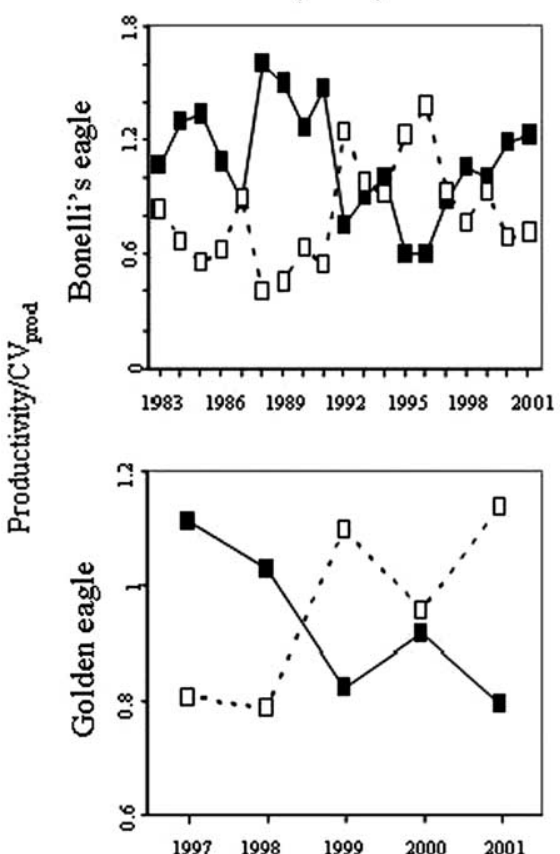

Low density area

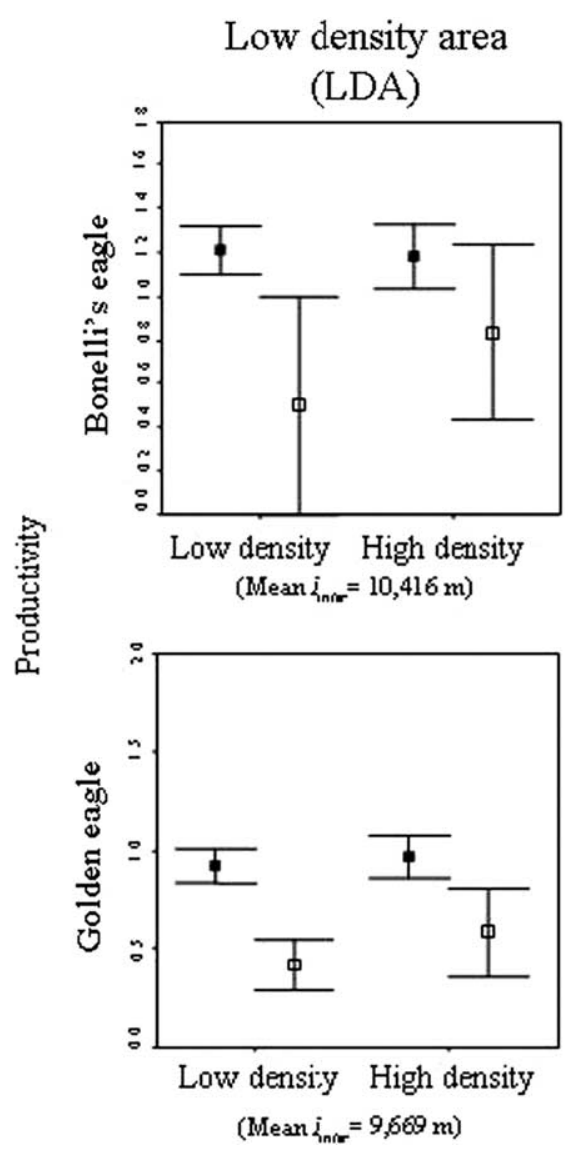

High density area

(HDA)
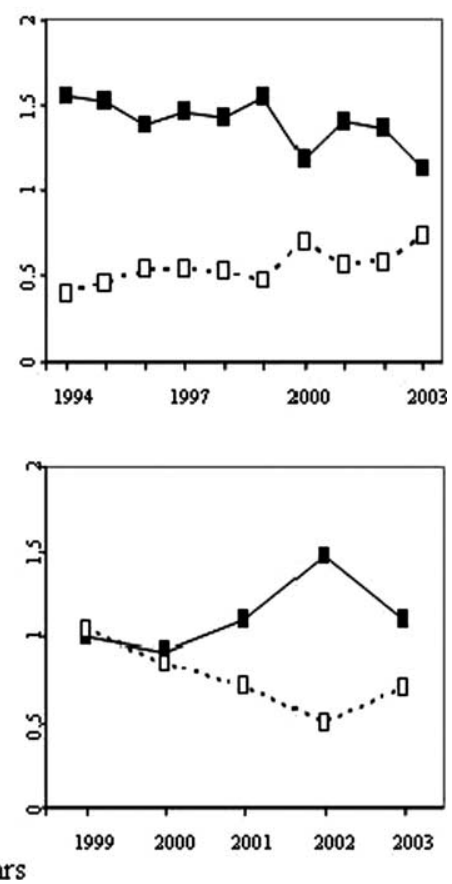

Fig. 2. Changes in mean productivity (solid lines and black points) and its coefficient of variation (dashed lines and white points) of golden and Bonelli's eagles in the two study areas (LDA and HDA).

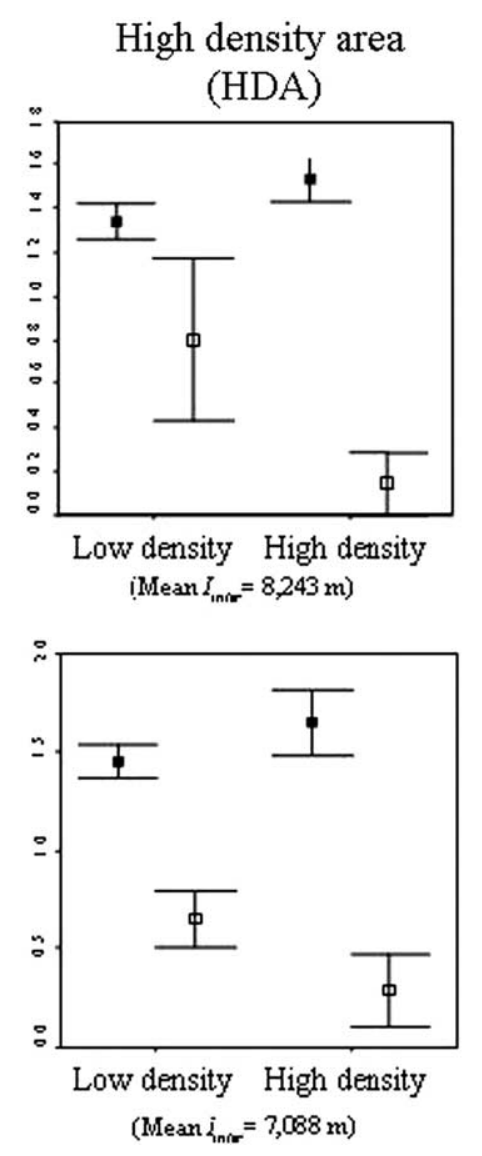

Fig. 3. Relationship between productivity and a) interspecific local breeding densities in two populations of Bonelli's eagles (LDA and HDA), and b) intraspecific local breeding densities in two populations of golden eagles (LDA and HDA). For graphic simplicity, breeding events are grouped as belonging to "low density" or "high density" territories (i.e. depending on whether the nearest distance to neighbours, I, was above or below the annual population average). Black dots represent pairs formed by two adults while white dots correspond to pairs formed by at least one subadult breeder. 
Table 3. GLMMs obtained to assess the relative contribution of habitat heterogeneity, intra- and interspecific densities and breeder's age on the productivity of the two populations of Bonelli's and golden eagle. Year and territory, included in models as random effects, were always not significant (p-range: 0.40-0.43); DEV:\% deviance explained by the model.

\begin{tabular}{|c|c|c|c|c|c|c|c|}
\hline & Effect & Estimate & SE & DF & $\mathrm{F}$ test & $\mathrm{p}$ & DEV \\
\hline \multicolumn{8}{|l|}{ Bonelli's eagle } \\
\hline \multirow[t]{3}{*}{ HDA } & subadults & 0.06 & 0.30 & 146 & 0.01 & 0.9215 & \multirow[t]{3}{*}{$13.37 \%$} \\
\hline & $\mathrm{I}_{\text {inter }}$ & $8.24 \mathrm{E}^{-6}$ & $6.97 \mathrm{E}^{-6}$ & 146 & 3.75 & 0.0546 & \\
\hline & $\begin{array}{l}\text { subadults }_{\text {subinter }} \\
>\mathrm{I}_{\text {in }}\end{array}$ & $-0.15 \mathrm{E}^{-3}$ & $0.67 \mathrm{E}^{-4}$ & 146 & 4.77 & 0.0306 & \\
\hline LDA & subadults & -1.14 & 0.26 & 242 & 19.77 & B0.0001 & $25.10 \%$ \\
\hline \multicolumn{8}{|l|}{ Golden eagle } \\
\hline \multirow[t]{3}{*}{ HDA } & subadults & 1.05 & 0.16 & 91 & 0.31 & 0.5770 & \multirow{3}{*}{$56.77 \%$} \\
\hline & $\mathbf{I}_{\text {intra }}$ & $-4.30 \mathrm{E}^{-6}$ & $0.14 \mathrm{E}^{-4}$ & 91 & 5.63 & 0.0197 & \\
\hline & subadults $>\mathrm{I}_{\mathrm{intra}}$ & $-0.11 \mathrm{E}^{-3}$ & $0.05 \mathrm{E}^{-3}$ & 91 & 4.85 & 0.0302 & \\
\hline LDA & subadults & -0.73 & 0.23 & 204 & 10.36 & 0.0016 & $4.42 \%$ \\
\hline
\end{tabular}

Younger, lower quality individuals are relegated to lower quality territories in several bird species (Newton 1998), but separating the effects of individual and territory quality is often not feasible because territory holders cannot be easily aged in many species (Krü ger and Lindströ $m$ 2001, Sergio and Newton 2003). In such cases, it is suggested that age-specific territory occupation and eventual productivity can be viewed as different points along the same continuum of demographic response to underlying habitat quality (Sergio and Newton 2003). However, here we have shown that territory and bird quality can be viewed as distinct components of breeding performance, at least in four populations of two eagle species largely differing in population structure and trends. Two recent studies have also tried to distinguish between these factors. Ferrer and Bisson (2003) analysed the contribution of age and territory on breeding performance of Spanish imperial eagles (Aquila adalberti ), finding inter-territory variability but no age-related effects. These authors, however, did not simultaneously test the two effects through multivariate analyses and recognised that the statistical power was too low. They finally concluded that territory quality is likely a composite of site and bird quality. A second study found both age and territory quality effects in Bonelli's eagles (Penteriani et al. 2003). However, the latter result must be interpreted with caution. The study covered all of Andalusia (southern Spain), including Granada province. It is an area about seven times greater than any one of our two study areas. Therefore, there is a great variability in altitude, topography, climate, vegetation, and human pressure (Penteriani et al. 2003, Gil-Sánchez et al. 2005). By pooling territories situated in such a variable habitat gradient into analyses, the significant variability in productivity between territories may be reflecting habitat heterogeneity at a regional rather than at a territory scale, thus making it unsuitable for a site-dependent population regulation framework. To illustrate this possibility, we would have found a significant effect of territory on the productivity of both eagle species, while controlling for age and year in GLMMs, if we had pooled our two neighbouring populations, which clearly differ in breeding parameters
(GLMMs for Bonelli's eagle, territory effect p B0.0001, age effect $\mathrm{p}=0.12$; golden eagle, territory effect $\mathrm{p}=$ 0.019, age effect $\mathrm{pB} \mathbf{B}$.0001). The problem of scale for detecting true habitat heterogeneity at the territory level was also highlighted by Dhondt et al. (1992).

\section{Habitat heterogeneity, age and survival}

Differences between territories may exist but are not directly linked with reproduction. Although the majority of studies on density-dependence are based on breeding performance, habitat heterogeneity may also be a consequence of sites differing in their suitability for survival (Rodenhouse et al. 1997, Breininger and Carter 2003, Lambrechts et al. 2004). However, this aspect has been largely unexplored, probably due to the difficulty in obtaining long-term territory-based survival estimates related to site-dependent population regulation (but see Serrano et al. 2005 for a colonial species). In the case of raptors with deferred plumage maturation such as our studied eagles, the proportion of subadult breeders can reasonably be used as a surrogate for mortality rates in breeding territories (reviewed by Whitfield et al. 2004a). Hence, we performed logistic regressions to assess whether the incorporation of subadults was or not uniform among territories. Results showed that the probability of recruiting subadult breeders strongly varied among territories in both species and populations (Table 4), thus supporting the existence of spatial variation in survival. It is worth noting that the deviance explained by this surrogate of survival (27-75\%, Table 4) is much higher than the deviance explained by the models built to explain variance in breeding performance (2-57\%, Table 2, 3). Under this scenario, higher mortalities associated with particular territories may increase their turn-over rates and therefore their probability of being occupied by young birds (or low quality individuals, in a more general sense) whose intrinsic lower quality (i.e. inexperience or lower competitive ability) reduces breeding success. Thus, habitat heterogeneity in productivity may arise not because sites differ 
Table 4. GLMs performed to detect differences between territories in recruitment of subadult breeders. The dependent variable was the presence (1) or not (0) of subadults in a given territory and year, using the binomial error and the logit link function to be related to territory (fitted as a fixed effect). Year effects resulted non significant in three out of four cases (p-value ranges: $0.02-0.57$ ). DEV: $\%$ deviance explained by the models.

\begin{tabular}{|c|c|c|c|c|c|c|c|c|}
\hline & \multicolumn{4}{|c|}{ Bonelli's eagle } & \multicolumn{4}{|c|}{ Golden eagle } \\
\hline & DF & $\mathrm{x}^{2}$ test & $\mathrm{p}$ & DEV & DF & $\mathrm{x}^{2}$ test & $\mathrm{p}$ & DEV \\
\hline HDA & 50 & 77.85 & 0.0071 & $49.03 \%$ & 48 & 107.86 & B0.0001 & $75.52 \%$ \\
\hline LDA & 28 & 46.47 & 0.0156 & $27.35 \%$ & 53 & 113.87 & B0.0001 & $53.95 \%$ \\
\hline
\end{tabular}

in suitability for reproduction but because of differences in factors affecting the survival of birds.

Adult mortality in both golden and Bonelli's eagles is mainly related to human persecution and artefacts such as power lines and windfarms (Real et al. 2001, Carrete 2002 reviewed by Whitfield et al. 2004a). These anthropogenic effects may create ecological traps in territories highly suitable for reproduction, thus having the potential for structuring populations and modelling their dynamics at large scales (Whitfield et al. 2004a, 2004b, Sergio et al. 2004). In addition, predation is not only a major component of breeding success in many other bird species but also a significant factor affecting adult survival (Newton 1998). Differences in predation risk between territories are expected to be common in wild conditions (Sergio et al. 2003) and thus site-dependent variability in adult survival may be an extended, but so far overlooked, factor to be seriously considered for the site-dependent population regulation framework.

\section{Effects of intra- and inter-specific competition}

Spatially structured social aspects such as the presence and distribution of competitors may constitute another overlooked, important source of heterogeneity affecting breeding performance independently of habitat features. We have shown here that proximity to other eagle territories affected productivity of both species in the area with higher eagle densities (HDA), in combination with age effects. Young golden eagles were negatively affected by distance to conspecific territories, while the productivity of young Bonelli's eagles was reduced at low distances to the larger species (golden eagle). Thus, young breeders seem to suffer from the effects of dominant conspecifics or from the effects of individuals of the dominant competing species. Intra-guild predation (Sergio et al. 2003) cannot explain this interspecific competition, since there are no known records of predation of Bonelli?s eagle nests by golden eagles. Two other non-mutually exclusive mechanisms may explain these patterns: direct inter-territorial competition causing food depletion, and agonistic interactions between close neighbours, which may also affect breeding performance. They have been shown to operate in colonial birds (Ferná ndez et al. 1998, Tella et al. 2001,
Forero et al. 2002), but less evidence is available for territorial species. Although further research is needed to identify their possible contribution, both mechanisms likely operate in our scenario of competition. In addition to the better known effects of intraspecific competition (Newton 1998), studies on sympatric raptors have shown high interspecific aggression by the larger species, interpreted as a result of competition for resources (García and Arroyo 2002, Hakkarainen et al. 2004). Moreover, although fitness costs of interspecific resource overlap have rarely been tested in the wild (Martin 1996), Gustafsson (1987) experimentally demonstrated that the reproductive output of a passerine bird species was dramatically affected by densities of a larger competing species, but not hardly by conspecific densities, again suggesting a role for food competition between coexisting species.

Susceptibility to interference and absolute foraging efficiency may change with age (Sutherland et al. 1986, Desrochers 1992, Gordon et al. 1996), with older individuals having a higher dominance rank (Piper 1997, Leary et al. 1999). Moreover, age differences in breeding performance may be masked by environmental variation, emerging more clearly in poor and intermediate food conditions (Laaksonen et al. 2002). In our study, the poor breeding output of subadults was associated with vicinity to other territories, suggesting that in high density situations (as is the case of the HDA), their lack of experience may decrease their competitive abilities when they interact with their neighbours (defending breeding sites and/or food resources), thus reducing their breeding performance.

\section{Concluding remarks}

As we have shown, apparent density-dependent patterns may arise from different processes and may also regulate populations. The identification of the mechanisms that are involved is relevant for both theoretical and applied ecology. Our results show that habitat heterogeneity plays a role in the population regulation of territorial species. However, contrary to many works dealing with this topic where the effects of individual and territory quality could not be separated, we have found that habitat heterogeneity in productivity may arise not 
because sites differ in suitability for reproduction, but instead because of differences in factors affecting survival of birds together with the spatial distribution of competitors.

Acknowledgements - We thank M. A. Sánchez, J. Bautista, P. Botella, J. F. Calvo, P. Cortés, S. Eguía, J. E. Martínez, F. Molino, T. Ortuñ o, M. Otero, I. Pagán, J. F. Sánchez Clemot, G. Valenzuela and the Forestry Guard of Murcia for their field assistance. J. Potti, J. A. Doná zar, D. Serrano, N. Selva and R. Calsbeek made many valuable suggestions for improving the manuscript. L. Bortolotti reviewed and improved the English version of the article. $M$. Carrete was supported by a predoctoral fellowship of the CONICET (Argentina) and a postdoctoral fellowship of the Fundación Séneca (Spain).

\section{References}

Bernstein, C., Krebs, J. R. and Kacelnik, A. 1991. Distribution of birds amongst habitats: theory and relevance to conservation. - In: Perrins, C. M., Lebreton, J. D. and Hirons, G. J. M. (eds), Bird population studies: relevance to conservation and management. Oxford Univ. Press, pp. 317-345.

Berryman, A. A. 2002. Population regulation, emergent properties, and a requiem for density-dependence. - Oikos 99: 600-606.

Berryman, A. A. 2004. Limiting factors and population regulation. - Oikos 105: 667-670.

Blanco, G., Fargallo, J. A., Cuevas, J. A. et al. 1998. Effects of nest-site availability and distribution on density-dependent clutch size and laying date in the chough Pyrrhocorax pyrrhocorax . - Ibis 140: 252-256.

Breininger, D. R. and Carter, G. M. 2003. Territory quality transitions and source -sink dynamics in a Florida scrub-jay population. - Ecol. Appl. 13: 516-529.

Carrete, M. 2002. The golden and the Bonelli's eagle in Mediterranean semiarid landscapes: spatial distribution, territorial occupancy, breeding success and conservation. - PhD thesis, Univ. of Murcia, Spain.

Carrete, M., Sánchez-Zapata, J. A., Martínez, J. E. et al. 2001. Distribució n espacial del águila-azor perdicera (Hieraaetus fasciatus ) y del águila real (Aquila chrysaetos) en la Región de Murcia. - Ardeola 48: 175-182.

Carrete, M., Sánchez-Zapata, J. A., Martínez, J. E. et al. 2002a. Factors influencing the decline of a Bonelli's eagle Hieraaetus fasciatus population in SE Spain: demography, habitat or competition? - Biodiv. Conserv. 11: 975-985.

Carrete, M., Sánchez-Zapata, J. A., Martínez, J. E. et al. 2002b. Predicting the implications of conservation management: a territorial occupancy model of a population of Bonelli's eagle in Spain. - Oryx 36: 349-356.

Carrete, M., Sánchez-Zapata, J. A., Calvo, J. F. et al. 2005. Demography and habitat availability in territorial occupancy of two competing species. - Oikos 108: 125-136.

Cody, M. L. 1985. Habitat selection in birds. - Academic Press.

Coulson, J. C. 1968. Differences in the quality of birds nesting in the centre and on the edges of a colony. - Nature 217: 478479.

del Hoyo, J., Elliot, A. and Sargatal, J. 1994. Handbook of the birds of the world. Vol II. - Lynx Edicions, Barcelona.

Desrochers, A. 1992. Age and foraging success in European blackbirds: variations between and within individuals. - Anim. Behav. 43: 885-894.

Dhondt, A. A., Kempenaers, B. and Adriaensen, F. 1992. Density-dependent clutch size caused by habitat heterogeneity. - J. Anim. Ecol. 61: 643-648.
Eccard, J. A. and Ylönen, H. 2003. Who bears the costs of interspecific competition in an age-structured population? - Ecology 84: 3284-3293.

Ferná ndez, C., Azkona, P. and Doná zar, J. A. 1998. Densitydependent effects on productivity in the Griffon vulture Gyps fulvus: the role of interference and habitat heterogeneity. - Ibis 140: 64-69.

Ferrer, M. and Doná zar, J. A. 1996. Density-dependent fecundity by habitat heterogeneity in an increasing population of Spanish imperial eagles. - Ecology 77: 69-74.

Ferrer, M. and Bisson, I. 2003. Age and territory-quality effects on fecundity in the Spanish imperial eagle (Aquila adalberti ). - Auk 120: 180-186.

Forero, M. G., Tella, J. L., Hobson, K. A. et al. 2002. Conspecific food competition explains variability in colony size: a test in Magellanic penguins. - Ecology 83: 34663475.

Forslund, P. and Pärt, T. 1995. Age and reproduction in birds: hypothesis and tests. - Trends Ecol. Evol. 10: 374378.

Forsman, D. 1999. The raptors of Europe and middle East. A handbook of field identification. - T and AD Poyser.

Fretwell, S. D. and Lucas, H. L. 1970. On territorial behaviour and other factors influencing habitat distribution in birds. I.

Theoretical development. - Acta Biotheor. 19: 16-36. García, J. T. and Arroyo, B. E. 2002. Intra- and interspecific agonistic behaviour in sympatric harriers during the breeding season. - Anim. Behav. 64: 77-84.

Gil-Sánchez, J. M., Moleó n, M., Otero, M. et al. 2004. A 9-year study of successful breeding in a Bonelli's eagle population in southern Spain: a basis for conservation. - Biol. Conserv. 118: $685-694$.

Gil-Sánchez, J. M., Moleón, M., Bautista, J. et al. 2005. Differential composition in the age of mates in Bonelli's eagle populations: the role of spatial scale, non-natural mortality reduction, and the age classes definition. - Biol. Conserv. 124: 149-152.

Gordon, I. J., Illius, A. W. and Milne, J. D. 1996. Sources of variation in the foraging efficiency of grazing rumiants. - Funct. Ecol. 10: 219-226.

Gustafsson, L. 1987. Interspecific competition lowers fitness in collared flycatchers Ficedula albicollis: an experimental demonstration. - Ecology 68: 291-296.

Hakkarainen, H. and Korpimäki, E. 1996. Competitive and predatory interactions among raptors: an observational and experimental study. - Ecology 77: 1134-1142.

Hakkarainen, H., Mykra, S., Kurki, S. et al. 2004. Competitive interactions among raptors in boreal forests. - Oecologia 141: $420-424$.

Haller, H. 1982. Raumorganisation und Dynamik einer Population des Steinadlers Aquila chrysaetos in der Zentralalpen. - Ornithol. Beobachter 79: 163-211.

Hawkins, B. A. and Berryman, A. A. 2000. Site-dependent regulation of population size: comment. - Ecology 81: 1166-1168.

Holt, A. R., Warren, P. H. and Gaston, K. J. 2004. The importance of habitat heterogeneity, biotic interactions and dispersal in abundance-occupancy relationships. - J. Anim. Ecol. 73: 841-851.

Hunt, W. G. and Law, P. R. 2004. Site-dependent regulation of population size: comment. - Ecology 81: 1162-1165.

Katzner, T. E., Bragin, E. A., Nnick, S. T. et al. 2003. Coexistence in a multispecies assemblage of eagles in central Asia. - Condor 105: 538-551.

Kokko, H., Harris, M. P. and Wanless, S. 2004. Competition for breeding sites and site-dependent population regulation in a highly colonial seabird, the common guillemot Uria aalge. - J. Anim. Ecol. 73: 367-376.

Krü ger, O. and Lindströ m, J. 2001. Habitat heterogeneity affects population growth in goshawk Accipiter gentilis. - J. Anim. Ecol. 70: 173-181.

Laaksonen, T., Korpimäki, E. and Hakkarainen, H. 2002. Interactive effects of parental age and environmental varia- 
tion on the breeding performance of Tengmalm's owls. - J. Anim. Ecol. 71: 23-31.

Lambrechts, M. M., Caro, S., Charmantier, A. et al. 2004. Habitat quality as a predictor of spatial variation in blue tit reproductive performance: a multi-plot analysis in a heterogeneous landscape. - Oecologia 141: 555-561.

Leary, J., Sullivan, K. A. and Hillgarth, N. 1999. Relationships among dominance, foraging proficiency and condition in juvenile dark-eyes juncos. - Auk 116: 1136-1141.

Littell, R. C., Milliken, G. A., Stroup, W. W. et al. 1996. SAS system for mixed models. - SAS Inst.

Martin, T. E. 1996. Fitness costs of resource overlap among coexisting bird species. - Nature 380: 338-340.

McCullagh, P. and Searle, S. R. 2000. Generalized linear and mixed models. - Wiley-Interscience.

Moilanen, A. and Hanski, I. 1998. Metapopulation dynamics: effects of habitat quality and landscape structure. - Ecology 79: 2503-2515.

Newton, I. 1998. Population limitation in birds. - Academic Press.

Newton, I., Marquiss, M., Weir, D. N. et al. 1977. Spacing of sparrowhawk nesting territories. - J. Anim. Ecol. 46: 425441.

Nilsson, S. G. 1987. Limitation and regulation of population density in the nuthatch Sitta europaea (Aves) breeding in natural cavities. - J. Anim. Ecol. 56: 921-937.

Ontiveros, D., Real, J., Balbontín, J. et al. 2004. Biología de la conservación del águila perdicera (Hieraaetus fasciatus) en España: investigación científica y gestión. - Ardeola 51: 461-470.

Pärt, T. 2001. The effects of territory quality on age-dependent reproductive performance in the northern wheatear, Oenanthe oenanthe. - Anim. Behav. 62: 379-388.

Pedrini, P. and Sergio, F. 2001. Density, productivity, diet, and human persecution of golden eagles (Aquila chrysä etos) in the central-eastern Italian Alps. - J. Raptor Res. 35: 40-48.

Penteriani, V., Balbontín, J. and Ferrer, M. 2003. Simultaneous effects of age and territory quality on fecundity in Bonelli's eagle Hieraaetus fasciatus. - Ibis 145: E77-E82.

Piper, W. H. 1997. Social dominance in birds. - Curr. Ornithol. 14: 125-187.

Real, J., Grande, J. M., Mañ osa, S. et al. 2001. Causes of death in different areas for Bonelli's eagle Hieraaetus fasciatus in Spain. - Bird Study 4: 221-228.

Rodenhouse, N. L., Sherry, T. W. and Holmes, R. T. 1997. Sitedependent regulation of population size: a new synthesis. - Ecology 78: 2025-2042.
Rodenhouse, N. L., Sherry, T. W. and Holmes, R. T. 2000. Sitedependent regulation of population size: reply. - Ecology 81: $1168-1171$.

Rosenzweig, M. L. 1979. Optimal habitat selection in 2-species competitive systems. - Fortschritte Zool. 25: 283-293.

Sánchez-Zapata, J. A., Carrete, M., Calvo, J. F. et al. 2000. Age and breeding success of a golden eagle (Aquila chrysaetos) population in SE Spain. - Bird Study 47: 235-237.

Schoener, T. W. 1983. Field experiments on interspecific competition. - Am. Nat. 122: 240-285.

Sergio, F. and Newton, I. 2003. Occupancy as a measure of territory quality. - J. Anim. Ecol. 72: 857-865.

Sergio, F., Marchesi, L. and Pedrini, P. 2003. Spatial refugia and the coexistence of a diurnal raptor with its intraguild owl predator. - J. Anim. Ecol. 72: 232-245.

Sergio, F., Marchesi, L., Pedrini, P. et al. 2004. Electrocution alters the distribution and density of a top predator, the eagle owl Bubo bubo. - J. Appl. Ecol. 41: 836-845.

Serrano, D., Oro, D.,Ursúa, E. et al. 2005. Colony size selection determines adult survival and dispersal preferences: Allee effects in a colonial bird. - Am. Nat. 166: E22 -E31.

Steenhof, K., Kochert, M. N. and Doremus, J. H. 1983. Nesting of subadult golden eagles in southwestern Idaho. - Auk 100: 743-747.

Sutherland, W. J., Jones, D. W. F. and Hadfield, R. W. 1986. Age differences in the feeding abilities of moorhens Gallinula chlorophus. - Ibis 128: 414-418.

Tella, J. L., Forero, M. G., Bertellotti, M. et al. 2001. Offspring body condition and immunocompetence are negatively affected by high breeding densities in a colonial seabird: a multiscale approach. - Proc. R. Soc. B 268: 1455-1461.

Tellería, J. L. 1986. Manual para el censo de los vertebrados terrestres. - Raices, Madrid.

Turchin, P. 1999. Population regulation: a synthetic view. - Oikos 84: 153-159.

Whitfield, D. P., Fielding, A. H., Mcleod, D. R. A. et al. 2004a. The effects of persecution on age of breeding and territory occupation in golden eagles in Scotland. - Biol. Conserv. 118: 249-259.

Whitfield, D. P., Fielding, A. H., Mcleod, D. R. A. et al. 2004b. Modelling the effects of persecution on the population dynamics of golden eagles in Scotland. - Biol. Conserv. 119: 319-333.

Wiens, J. A. 1989. The ecology of bird communities. - Cambridge Univ. Press. 